\title{
Farmers' Knowledge on Pesticide Application in Vegetable Cultivation
}

\author{
Shekha Nasrin, Muhammad Humayun Kabir, Md. Mahbubul Alam, Md. Saiful Islam* \\ Department of Agricultural Extension and Information System, Sher-e-Bangla Agricultural University, Dhaka, Bangladesh \\ Email address: \\ mdsaiful.sumon52@gmail.com (Md. S. Islam) \\ ${ }^{*}$ Corresponding author
}

To cite this article:

Shekha Nasrin, Muhammad Humayun Kabir, Md. Mahbubul Alam, Md. Saiful Islam. Farmers' Knowledge on Pesticide Application in Vegetable Cultivation. International Journal of Applied Agricultural Sciences. Vol. 5, No. 6, 2019, pp. 144-151.

doi: $10.11648 /$ j.ijaas.20190506.13

Received: August 21, 2019; Accepted: September 20, 2019; Published: December 4, 2019

\begin{abstract}
The objectives of this study were to describe some selected characteristics of the vegetable farmers; to assess the extent of farmers' knowledge on pesticide application in vegetable cultivation, and to determine the factors that significantly influences farmers' knowledge on pesticide application in vegetable cultivation. The study was conducted with randomly selected 109 vegetable farmers in Ganna union under Jhenaidah sadar upazila of Jhenaidah district. A pre-tested interview schedule was used to collect data from the respondents during $10^{\text {th }}$ February to $13^{\text {th }}$ March, 2018. Knowledge on pesticide application in vegetable cultivation was the dependent variable and the dependent variable was measured by 15 different questions on knowledge on pesticide application in vegetable cultivation and the nine selected characteristics of the respondents considered as the independent variables of the study. Majority (56.8 percent) of the respondents had medium knowledge while 23.9 percent and 19.3 percent of them had low and high knowledge on pesticide application in vegetable cultivation. Three characteristics of the respondent's viz. education, training in vegetable cultivation and extension media contact had significant positive contribution to their knowledge on pesticide application in vegetable cultivation. But farm size, land under vegetable cultivation, income from vegetable cultivation, organizational participation and time spend in vegetable cultivation had no significant contribution to their knowledge on pesticide application in vegetable cultivation.
\end{abstract}

Keywords: Knowledge, Pesticide Application, Vegetable Cultivation and Bangladesh

\section{Introduction}

Bangladesh is basically an agricultural country. The economy of Bangladesh is largely dependent on agriculture. Sustained government investment in irrigation facilities, rural infrastructure, and agricultural research and extension services has helped Bangladeshi farmers achieve dramatic increases in agricultural production. The process of agricultural production is, however, underpinned by the increasing use of agrochemicals and multiple cropping. And while significant production transformation has been achieved and food production has more than doubled since independence in 1971, these have mostly supported the country's large population base rather than uplifting the living standards of the average citizen. Food security still remains a major development issue. Thus, the government of Bangladesh has called for a departure from "rice- led" growth to a more diversified production base that includes several non-rice crops [1].

Rice occupies about 77.46 percent of total cropped area and the remainder 22.54 percent of the total cropped area is occupied by other non-rice crops which include vegetables, pluses, oilseeds and spices and condiments (Table 1). Monoculture of rice for prolonged periods has led to a number of serious physical and biological problems as formation of plough plan in wet land cultivation, declining bearing power of soils, increasing incidence of pest and diseases and declining soil fertility resulting from sulpher and zinc deficiency, continuous rice cultivation has also nutritional impact i.e. it reduces the production of pluses, oilseeds and vegetables which are major sources of protein, minerals and vitamins and it causes nutritional imbalance in human diet as well as in animal diet [2]. 
Table 1. Areas irrigated under different crops in 2017.

\begin{tabular}{llll}
\hline Crops & & Area (ha) & Percent \\
\hline \multirow{2}{*}{ Rice } & Aus & 1865000 & 12.50 \\
& Aman & 1162000 & 8.39 \\
& Boro & 9560000 & 69.07 \\
Total rice cropped area & 10722000 & 77.46 \\
Wheat & 855000 & 6.18 \\
Potato & 587000 & 4.24 \\
Vegetables & 584000 & 4.22 \\
Sugarcane & 95000 & 0.69 \\
Cotton & 11000 & 0.08 \\
Others & 9888000 & 7.14 \\
Grand Total & 13842000 & 100 \\
\hline
\end{tabular}

Sources: [3].

Vegetables are the most important component of our food and are rich in vitamins, minerals and fibers essential for human health. A number of vegetables are considered as protective food items which prevent many disease and ailments like, dislipidemea, cardiac disease, diabetes and constipation. Vegetables can be grown round the year utilizing homestead lands which yield high economic return and help in employment and income generation.

Vegetables are cultivated in 4.22 per cent of the total cultivatable land. Besides this, the premises of houses, tin sheds and roof tops are used for vegetable cultivation. Vegetable production has increased five times in the past 40 years. Bangladesh has scored 3rd in global vegetable production, next to China and India [4]. The farmers are getting large amount of money from vegetable production which is changing their life [5]. In Bangladesh, vegetables are grown generally in summer and winter seasons. Among them, some vegetables are grown round the year. Most of the vegetables such as sweet gourd, white gourd, bitter gourd, snake gourd, cucumber etc. grown in summer season are indigenous in nature whereas maximum winter vegetables like cabbages, cauliflower, tomato, etc. are exotic in nature and some vegetables such as brinjal, amaranth, bottle gourd, bean, pointed gourd etc, are grown in both of the seasons. But it is a matter of sorrow that the quality of vegetables intake is very negligible in Bangladesh.

Average intake meets only 80 percent of Calorie, 58 percent of Vitamin A, 50 percent of Riboflavin and 51 percent of Vitamin $\mathrm{C}$ requirements as reported by the Nutrition survey of Bangladesh [6]. The Production of vegetables in Bangladesh is not sufficient that per capita/day available is hardly $32 \mathrm{gm}$ whereas the requirement is estimated to $220 \mathrm{gm}$. This gap is probably one of the main reasons for widespread malnutrition in the country. Recent studies have shown that Vitamin A is not only important to prevent blindness but also has effect on digestion of food, child morbidity and mortality. It is estimated that about 80 percent of the population suffers from Vitamin $\mathrm{C}$ deficiency [7]. Being a poor nation, it is difficult to overcome such a big malnutrition problem by eating fish, meat, egg, butter, ghee. But vegetables can play a very important role to improve the nutritional level of the rural people in the country which is almost entirely overlooked. In other words, problems related to malnutrition can easily be overcome by eating adequate quantity of vegetables, which require some adjustment in the dietary habit and also by increasing per yield of vegetable [8].

The above mentioned discussion simply indicates the importance of vegetable in our daily life from nutritional point of view. From the economic point of view, vegetables should be cultivated for higher farm income, increasing cropping intensity, improvement of socio-economic condition and protection of environmental pollution, development of healthy and efficient manpower; higher export potentials, reducing import and enhancement of industrialization, employment generation, and less consumption of cereals, which leads to overcome food shortage. According to Agricultural Marketing Department, Bangladesh earned Tk. 31 core by exporting 8 thousand tons of vegetable [8].

In Bangladesh, millions of farmers earn their living by growing vegetable crops almost throughout the year. To protect the crops from pest damages the farmers incur more than $30 \%$ of the cultivation costs to purchasing pesticides only [2]. Vegetable farmers, particularly smallholders, confront a number of constraints in the vegetable production. The production risks are high primarily because of considerable production losses caused by pests. These are estimated to be about $30 \%$ of the total vegetable output [9]. There are several pests that attack vegetables such Leaf miner, Aphids, Thrips, Cutworms Armyworms Cabbage looper Beetles Earworms and hornworms Green vegetable bugs Spider mites Stem borers Root-knot nematodes etc. [10].

To control pests farmers use high amount of pesticide on vegetable. There are many other negative consequences of using higher doses of pesticides. Most devastating ecological imbalance is caused due to indiscriminate use of pesticides. Pesticides affect fishes, living in the river tank, pond, etc. It is proven that dangerous pesticides are present at an unacceptable level in the fishes of the Bay of Bengal which is too much harmful for human health. Fishes alone contributed to an unacceptable level of insecticides among Bangladeshi people which is five times more than their American counterpart [11]. Excessive use of chemical fertilizer and pesticide also reduce water conservation capacity of soil [12, 13]. Pesticide population and fertilizer wastes also caused microbial degradation in soil [14].

Since the farmers are the ultimate users of pesticides it is necessary to know their knowledge about pesticide use. Over dose and frequent use of pesticide may be a threat for agroecology as well as human body. The farmers of Bangladesh do not use of pesticide judiciously, which may pose a serious threat of the environment. Therefore, there is a need to conduct a research to determine farmers' knowledge on pesticide use in vegetable cultivation.

Pesticides are a concern for sustainability of environment and global stability [15]. Consumers should consider going to organic because pesticide on foods are far more dangerous than was thought to the human brain [16]. The following objectives were framed out in order to give an appropriate 
track to the research work.

1. To describe some selected characteristics of the vegetable farmers;

2. To assess the extent of farmers knowledge on pesticide application in vegetable cultivation; and

3. To determine the factors that significantly influences farmers' knowledge on pesticide application in vegetable cultivation.

\section{Methodology}

\subsection{Locale of the Study}

Jhenaidah District was purposively selected as the locale of the study. There are 6 upazilas in the district. Among those Jhenaidah Sadar upazila was selected purposively for this study. Jhenaidah is a district in southwestern Bangladesh. It is a part of the Khulna division. It is an area $1964.77 \mathrm{~km}^{2}$. It is bordered by the Kushtia district to the north, to the south by Jessore district and West Bengal (India), to the east by Rajbari district and Magura district and to the west by Chuadanga district and West Bengal (India) on the west. However, Ganna union of sadar upazila was finally selected randomly for conducting the study. Four villages of Ganna union namely Kuthidurgapur, Chandipur, Kalohati and Asostholi were selected for the study.

\subsection{Population and Sampling}

A list of vegetable farmers of the study area was prepared by the researchers herself with the help of the Sub-Assistant Agriculture Officer (SAAO) of Jhenaidah Sadar upazila Agriculture Office. The list comprised a total number of 273 vegetable farmers in the study area. These farmers constituted the population of this study. To make a respective sample 40 percent of the population was selected proportionately random sampling technique [17]. Thus, one hundred nine (109) vegetable farmers were selected as the sample of the study. Besides this 10 percent of the samples were selected randomly as reserves who were supposed to be interviewed only when a respondent in the original sample list was unavailable during data collection. The village-wise distribution of the population and sample of farmers are shown in Table 2.

Table 2. Distribution of the vegetable farmers constituting the population, sample and reserve list in different villagers in Ganna Union.

\begin{tabular}{llll}
\hline \multirow{2}{*}{ Name of Villages } & No. of farmers & \multirow{2}{*}{ Reserve List } \\
\cline { 2 - 3 } & Population & Sample size & \\
\hline Kuthidurgapur & 80 & 32 & 3 \\
Chandipur & 60 & 24 & 2 \\
Kalohati & 75 & 30 & 3 \\
Asostholi & 58 & 23 & 2 \\
Total & 273 & 109 & 10 \\
\hline
\end{tabular}

\subsection{Instrument of Data Collection}

In a social research, preparation of an interview schedule for collection of information with very careful consideration is necessary. Keeping this fact in mind the researcher prepared an interview schedule carefully for collecting data from the respondents. Objectives of the study were kept in view while preparing the interview schedule. Simple and direct questions and different scales were used to obtain information. Both open and closed form questions were designed to obtain information relating to qualitative variable which was finally be measured by ranking score. The initially prepared interview schedule was pre-tested among 15 respondents of the study area. The pretest was helpful to find out gaps and to locate faulty questions and statements. Alterations and adjustments were made in the schedule on the basis of experience of the pretest. Questions were asked systematically and explanations were made whenever it is necessary. The respondents were interviewed at their leisure time so that they can give accurate information in a cool mind.

\subsection{Data Collection Procedure}

Data were collected through personal interviewing by the researcher herself. The researcher made all possible efforts to establish rapport with the respondent so that they could feel ease and comfort to response the questions in the schedule. Necessary steps were taken to explain the purpose of the study to the respondents and their answers were recorded sincerely. If any respondent felt difficulty in understanding any question, care was taken to help him getting understood. The researcher did not face any serious problem in data collection. The data collection took 31 days from $10^{\text {th }}$ February to $13^{\text {th }}$ March, 2018. The collected data were complied, tabulated and analyzed. Qualitative data were converted into quantitative form by means of suitable scoring whenever needed.

\subsection{Measurement of Independent Variables}

\subsubsection{Level of Education}

Education was measured as the ability of an individual vegetable farmer to read and write or formal education (school/college) completed up to a certain standard. It was expressed in terms of year of schooling. A score of one (1) was assigned for each year of schooling completed. For example, if the respondent passed the SSC examination his education score was given as 10 , if passed the final examination of class seven, his education score was given as 7 , if the respondent did not know how to read and write, his education score was given as ' 0 ' (zero). A score of 0.5 (half) was given to that respondent who could signature his name only.

\subsubsection{Farm Size}

Farm land is the most important capital of a farmer and the farm size has influence on many personal characteristics of a farmer. Farm size of the farmer was measured by the land area possessed by him. The unit of measurement was hectares.

\subsubsection{Land Under Vegetable Cultivation}

Area under vegetable cultivation was measured by the area 
of land under her management only for vegetable cultivation. The area was estimated in terms of full benefit to farmers or her family. The unit of measurement was in decimal.

\subsubsection{Off-farm Income}

Income from off-farm of the respondents was measured in thousand taka on the basis of total annual income from the other sources such as business, services etc. It was expressed in ' 000 ' taka.

\subsubsection{Income from Vegetables Cultivation}

Income from vegetable cultivation of the respondents was measured in thousands taka on the basis of total annual income from vegetable cultivation.

\subsubsection{Training on Vegetable Cultivation}

Training received was measured by total number of days of agricultural training on vegetable production received by the respondents in his/her life. One score was assigned for each day of training received by the respondent.

\subsubsection{Agricultural Extension Media Contact}

The agricultural extension media contact of a respondent was measured on the basis of the extent of his contact with selected seven media in a scale ranging from- regularly, frequently, occasionally, rarely and not at all. The responses were scored as 4, 3, 2, 1 and 0 respectively. The use of agricultural extension media contact score of the respondents ranged from 0 to 24 where, 0 indicates no use and 24 indicates very high use.

\subsubsection{Organizational Participation}

Organizational participation of a respondent was measured by computing an organizational participation score according to his/her nature and duration of participation in five (5) selected different organizations up to the time of interview. The organizational participation score was evaluated for each respondent on the basis of his/her membership with five different types of organization. The following scale was used for computing the organizational participation score. The nature of participation was the respondent no participation, participation as ordinary member, participation as executive member and participation as secretary/president. The score was $0,1,2$ and 3 respectively. Organizational participation score of a respondent was determined by adding together the scores obtained from each of the five types of participation. Organizational participation score of the respondents could range from 0 to 15 , where, 0 indicating no participation and 15 indicating high participation.

\subsubsection{Time Spends in Vegetables Farming}

Time spend in vegetables farming of the vegetable farmers was measured by hours per week.

\subsection{Measurement of Dependent Variable}

For measuring the knowledge on vegetables production activities of the respondents, 15 questions were included in the interview schedule. Each question contains 2 marks. The questions were asked based on three aspect of pesticide application which are frequency of pesticide application, doses of pesticide application and precautionary measures of pesticide application respectively in the scale in order to assess the knowledge on pesticide application. For correct answer respondents were given full marks. If respondents are unable to provide the answer than he or she get zero marks. Finally total marks of 15 questions are calculated and measure knowledge on vegetable production activities.

\subsection{Data Processing}

The collected raw data were examined thoroughly to detect errors and omissions. As a matter of fact the researcher made a careful scrutiny of the completed interview schedule to make sure that necessary data were entered as complete as possible and well arranged to facilitate coding and tabulation. Very minor mistakes were detected by doing this, which were corrected promptly.

\subsection{Coding and Tabulation}

Having consulted with the research supervisor and cosupervisor, the investigator prepared a detailed coding plan. In case of qualitative data, suitable scoring techniques were followed by putting proper weight age against each of the traits to transform the data into quantitative forms. These were then tabulated in accordance with the objective of the study.

\subsection{Categorization of Data}

Following coding operation, the collected raw data as well as the respondents were classified into various categories to facilitate the description of the independent and dependent variables. These categories were developed for each of the variables by considering the nature of distribution of the data and extensive literature review.

\subsection{Statistical Analysis}

The statistical measures such as range, mean, standard deviation, percentage, rank order were used for describing both the independent and dependent variables. Tables were also used in presenting data for clarity of understanding. Initially, multiple regressions (SPSS v 20) were run to determine the contribution to the selected characteristics of the vegetable farmers with their knowledge on pesticide application in vegetable cultivation. To find out the contribution of selected characteristics of the vegetable growers to their knowledge on pesticide application in vegetable cultivation, multiple regressions analysis was used. Five percent (0.05) level of probability was used as the basis for rejection of a null hypothesis throughout the study. Coefficient values significant at 0.05 level is indicated by one asterisk (*), and that at 0.01 level by two asterisks $(* *)$.

\section{Findings and Discussion}

\subsection{Selected Characteristics of the Farmers}

Data contained in the Table 3, reveal the salient features of 
the characteristics of the vegetable farmers in order to have an overall picture of these characteristics at a glance. However, for ready reference, separate tables are provided while presenting categorizations, discussing and /or interpreting results concerning each of the characteristics in this chapter.

Table 3. The salient features of the selected characteristics of the farmers.

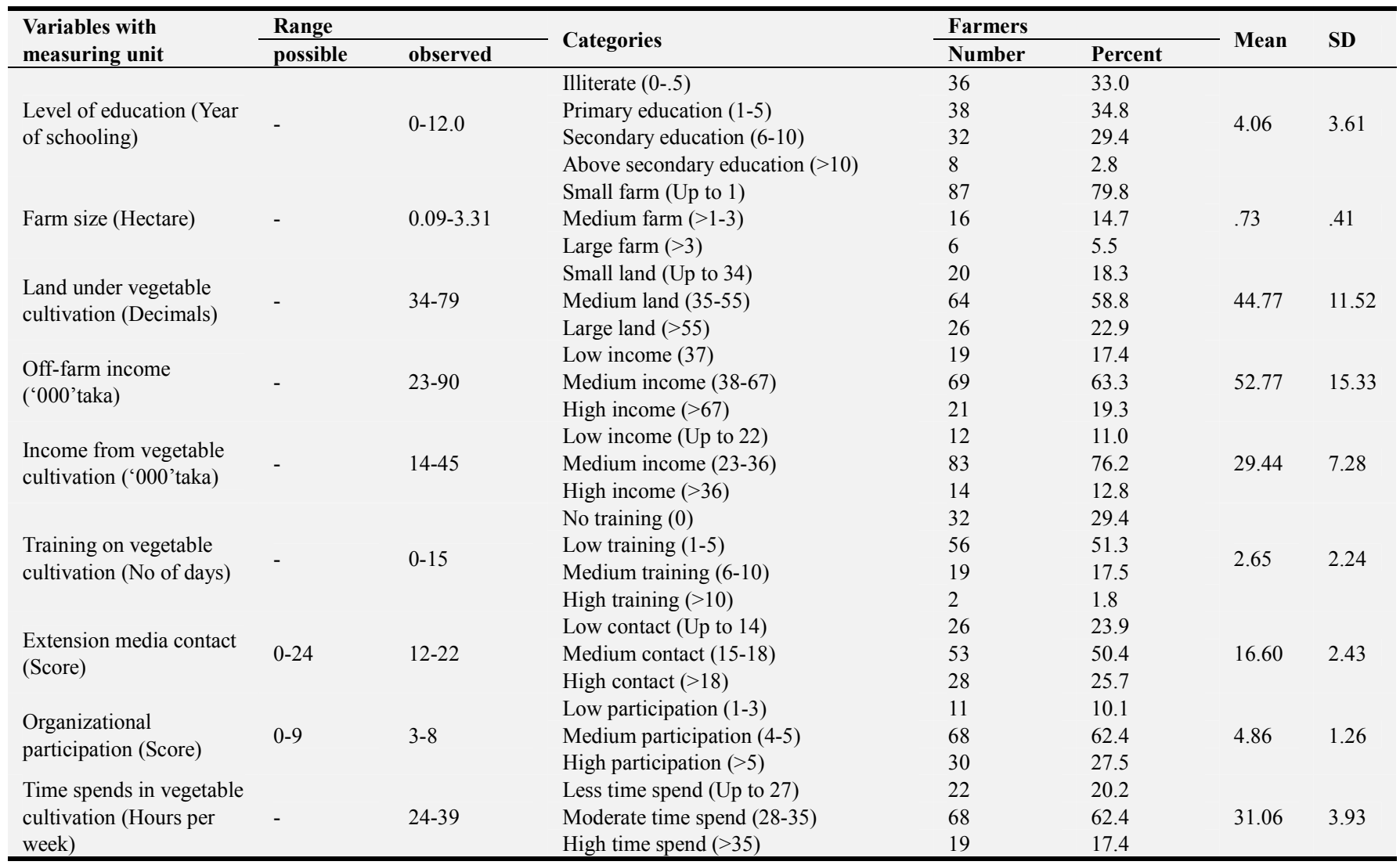

Table 3 revealed that most $(34.8 \%)$ of the farmers were in primary level of education while only $(8 \%)$ of the farmers were in above secondary level of education. The Majority $(79.8 \%)$ of the farmers had small size of land. Most of the farmers had medium land under vegetable cultivation. Near about $(63.3 \%)$ of the farmers had medium off-farm income where as $76.2 \%$ of the farmers had medium income from vegetable cultivation. Overwhelming $(51.3 \%)$ of the respondents had low training on vegetable cultivation and near about half of the farmers had medium extension media contact. Medium organizational participation had highest 62.4 percent and $62.4 \%$ of the farmers had spent medium time in vegetable cultivation.

\subsection{Farmers' Knowledge on Pesticide Application in Vegetable Cultivation}

Computed scores of the farmers about Knowledge on pesticide application in vegetable cultivation ranged from 13 to 22 with mean of 16.28 and standard deviation of 2.24 . On the basis of Knowledge on pesticide application, the respondents were classified into three categories namely low knowledge (up to 14), medium knowledge (15 to 18) and high knowledge (above 18) as follows in Table 4.

Table 4. Distribution of vegetable farmers according to their knowledge.

\begin{tabular}{llll}
\hline \multirow{2}{*}{ Categories } & Score & Vegetable farmers & Percent \\
\cline { 2 - 4 } & & Number & Mean \\
\hline Low knowledge & Up to 14 & 22 & 23.9 \\
Medium knowledge & 15 to 18 & 60 & 56.8 \\
High knowledge & Above 18 & 21 & 19.3 \\
Total & & 109 & 100 \\
\hline
\end{tabular}

Data presented in Table 4 indicate that most (56.8 percent) of the respondents had medium knowledge against 23.9 percent of the respondents had low knowledge on pesticide application in vegetable cultivation and 19.3 percent had high knowledge on pesticide application in vegetable cultivation.
Thus, a proportion (80.7 percent) of the vegetable farmers had medium to low knowledge on various aspects of pesticide application in vegetable cultivation. Knowledge is to be considered as vision of an explanation in any aspect of the situation regarding vegetable cultivation. It is act or state 
of understanding; clear perception of fact or truth, that helps an individual to foresee the consequence he may have to face in future. It makes individuals to become rational and conscious about related field. To perform optimum production, vegetable farmers should have adequate knowledge on different aspects of pesticide application in vegetable cultivation.

\subsection{Contributing Factors Related to the Knowledge on Pesticide Application in Vegetable Cultivation}

In order to estimate the knowledge on pesticide application in vegetable cultivation from the independent variables, multiple regression analysis were used which is shown in the Table 5 .

Table 5. Multiple regression coefficients of contributing factors related to the Knowledge on pesticide application in vegetable cultivation.

\begin{tabular}{llll}
\hline Dependent variable & Independent variables & $\boldsymbol{\beta}$ & $\boldsymbol{p}$ \\
\hline & Education & 0.590 & $0.000^{* *}$ \\
& Farm size & -0.002 & 0.956 \\
& Land under vegetable cultivation & 0.061 & 0.301 \\
Farmers' Knowledge on & Off-farm income & -0.081 & 0.531 \\
pesticide application in & Income from vegetable cultivation & 0.005 & 0.921 \\
vegetable cultivation & Training in vegetable cultivation & 0.199 & $0.002^{* *}$ \\
& Extension media contact & 0.045 & $0.035^{*}$ \\
& Organizational participation & 0.004 & 0.950 \\
& Time spend in vegetable cultivation & 0.125 & 0.344 \\
\hline
\end{tabular}

* Significant at $\mathrm{p}<0.05 ; * *$ Significant at $\mathrm{p}<0.01$

The data in Table 5 shows that there is a significant contribution of the selected characteristics (education, training in vegetable cultivation and extension media contact of the farmers. Of these, education and training in vegetable cultivation were the most important contributing factors (significant at the $1 \%$ level of significant) and extension media contact (significant at 5\% level of significant) while coefficients of other selected variables don't have any contribution on pesticide application in vegetable cultivation.

The value of $\mathrm{R}^{2}$ is a measure of how of the variability in the dependent variable is accounted for by the independent variables. So, the value $\mathrm{R}^{2}=0.576$ means that independent variables accounts for $57 \%$ of the variable in knowledge on pesticides application in vegetable cultivation.

The $\beta$-value of education is $(0.590)$. So, it can be stated that with the increase of education, farmers' knowledge on pesticide application in vegetable cultivation will also increase. Considering the effects of all other predictors are held constant.

Based on the above finding, it can be said that education plays an important role in pesticide application in vegetable cultivation. By increasing education people are able to know about how pesticide application in vegetable field, learn about its negative side, become conscious, get benefited and so on, which increase the knowledge on pesticide application in vegetable cultivation. The finding is similar to the studies [18-23].

The $\beta$-value of training on pesticide application in vegetable cultivation is (0.199). This implies that with the increase of training in vegetable cultivation of the farmers will increase their knowledge on pesticide application in vegetable cultivation. Considering the effects of all other predictors are held constant.

Based on the above finding, it can be said that training helps the farmers to acquire deep knowledge and improve the skills about the respected aspects. Trained farmers can cope with and handle smoothly the adverse situation in their vegetable cultivation. So, they show favorable attitude towards knowledge on pesticide application in vegetable cultivation. The finding is similar to the studies [24-26].

The $\beta$-value of agricultural extension media contact is (0.045). This implies that with the increase of extension media contact of the farmers will increase their knowledge on pesticide application in vegetable cultivation. Considering the effects of all other predictors are held constant.

Based on the above finding, it can be said that extension media contact plays an important role in knowledge on pesticide application in vegetable cultivation. By continuous contact with different extension agents are concerned about pesticide application in vegetable cultivation, become trained, get benefited and so on, which increase the knowledge on pesticide application in vegetable cultivation. The finding is similar to the studies [27-30].

\section{Conclusion and Recommendations}

The findings revealed that majority (81\%) of the respondents had low to medium knowledge on pesticide application in vegetable cultivation at the study area. This fact leads to the conclusion that overall knowledge on pesticide application in vegetable cultivation by the farmers was not satisfactory. There is huge scope for increasing knowledge on pesticide application in vegetable cultivation by the respondents. Education, training in vegetable cultivation and extension media contact of the respondents showed the important contribution factor to their knowledge on pesticide application in vegetable cultivation. The result concluded that establishment of more school; more training facilities and farmers' involvement with those will increase farmers' knowledge on pesticide application in vegetable cultivation. Training helps the farmers to acquire deep knowledge on pesticide application in vegetable cultivation. Therefore it may be recommended that attempts should be taken to establish adult learning centre to increase educational level as well as pesticide application knowledge in vegetable cultivation of the farmers. Education helps an 
individual to realize the present and future needs at the personal, social and national levels. Government and nongovernment organizations may conduct training and awareness programs according to need of vegetable farmers for increasing their knowledge on pesticide application in vegetable cultivation.

\section{References}

[1] Hoque, M. E. 2000. Crop diversification in Bangladesh. In: M. K. Papadimitriou and F. J. Dent (Eds.). Crop diversification in the Asia-Pacific region, Bangkok.

[2] Karim, A. 2011. IPM: Changing the Vegetable Pest Management System in Bangladesh. Phytopathology 101: S227.

[3] BBS (Bangladesh Bureau of Statistics). 2017. Statistical Yearbook of Bangladesh, Bangladesh Bureau of Statistics, Statistical Division, Ministry of Planning, Government of the People's Republic of Bangladesh, Dhaka.

[4] FAO (Food and Agriculture Organization). 2017. Bangladesh vegetable production has increased five times in 40 years. Source: thefinancialexpress-bd.com. Publication date: $1 / 26 / 2017$.

[5] Hossain, M. S. 2017. Revolution in vegetable production in Bangladesh. The Financial Express. (Accessed date: 26. 03.2017).

[6] INFS 2013. Nutrient Content of Bangladesh Food, Institute of Nutrition and Food Science, University of Dhaka, Bangladesh.

[7] HRDP 2013. Training Manual Winter Vegetable and Spices Production FAO/UNDP/ASDB project BGD/87/025, Dhaka. Department of Agricultural Extension (DAE) and Bangladesh Agricultural Development Corporation, Dhaka. pp. 43-47.

[8] Mahasin, M. 1996. Adoption of High Yielding Winter Vegetable Varieties by the Farmers of Moinamaty Union under Comilla District. MS (Agril. Ext. Ed.) Thesis, IPSA, Gazipur.

[9] KAUSHIK, N. 2009. Management of diseases in vegetable crops by using Trichoderma and Pseudomonas. Phytopathology 99: S62.

[10] Fores, J. S. 2017. 13 Common Pests of Leafy Vegetables: Photos, Prevention, and Control.

[11] Sarker, T. M. 1993. Fisheries Resources on the brink of Danger. The Bangladesh Observer, 24 May 93: 8.

[12] Khaleque, A. 1993. Bangladesh Research Develops New Fertilizers, The Bangladesh Observer, 26 September 93: 12. Rahman, M. M. 1986. Correlation of Adoption of Improved Practices in Transplanted Aman Rice. Bangladesh Journal of Extension Education, 1 (2): 75.

[13] Rezauddin, M. 1994. The issues of agrochemicals and environment. Towards sustainable agricultural development. A paper presented at the seminar held at BRAC on January 5, Dhaka, Bangladesh.

[14] Garg, N., Gagr, K. L. and Kukeerji, K. G. 1994. Microbiological degradation of environmental pollutants. In: Recent advances in biodeterioration and biodegradation. Vol.
2. pp. 327-362.

[15] Hakeem and Khalid Rahman 2016. Effects of Pesticides on Environment. DOI: 10.1007/978-3-319-27455-3_13.

[16] Donnelly, L. 2017. Pesticides in food may damage the brain. The Daily Telegraph, 3 June 17.

[17] Rakib, T. M., Kabir, M. H. Islam, M. R. and Islam, M. S. 2019. Profitability of Vegetable Cultivation by the Integrated Pest Management (IPM) Farmers. American Journal of Agricultural Research. https://escipub.com/american-journalof-agricultural-research.

[18] Akhter, S. 2003. Comparison Between Knowledge and Skill of Women Led FFS of RDRS and Non-FFS Farmers. M. S. (Ag. Ext. Ed). Thesis, Department of Agricultural Extension Education, Bangladesh Agricultural University, Mymensingh.

[19] Hoque, M. F. 2005. Adoption of Selected Modern Boro Rice Varieties by the Farmers in Three Selected Villages of Sadar Upazila of Mymensing District. MS. (Ag. Ext. Ed.) Thesis. Department of Agricultural Extension Education, Bangladesh Agricultural University, Mymensingh.

[20] Islam, M. A. 2005. Farmers' Knowledge and Practices in Using IPM Crop Production. M. S. Ag. Ext. Ed). Thesis, Department of Agricultural Extension Education, Bangladesh Agricultural University, Mymensingh.

[21] Rahman, M. Z. 2006. Knowledge of the Farmers' on Prawn Culture in a Selected Area of Khulna District. M. S. (Ag. Ext. Ed). Thesis, Department of Agricultural Extension Education, Bangladesh Agricultural University, Mymensingh.

[22] Rahman, M. S. 2004. Extent and Level of Knowledge of Farmers on HYV Boro Rice Cultivation Practices. M. S. (Ag. Ext. Ed) Thesis, Department of Agricultural Extension Education, Bangladesh Agricultural University, Mymensingh.

[23] Roy, K. K. 2005. Farmers' Knowledge on Boro Rice Cultivation in Some Selected Areas of Dinajpur District. M. S. (Ag. Ext. Ed). Thesis, Department of Agricultural Extension Education, Bangladesh Agricultural University, Mymensingh.

[24] Haque, M. M. 2003. Farmer's Adoption of Modern Maize Cultivation Technologies. M. S. (Ag. Ext. Ed.) Thesis, Department of Agricultural Extension Education, Bangladesh Agricultural University, Mymensingh.

[25] Islam, M. S. 2002. Adoption of Modern Agricultural Technologies by the Farmers of Sanduip. M. S. (Ag. Ext. Ed.) Thesis, Department of Agricultural Extension Education, Bangladesh Agricultural University, Mymensingh.

[26] Islam, M. N. 2008. Knowledge on Vegetables Production Activities by Woman Members in Homestead Area under World Vision Project. M. S. (AEIS). Thesis, Department of Agricultural Extension and Information System, Sher- eBangla Agricultural University, Dhaka.

[27] Islam, M. S., Kabir, M. H., Ali, M. S., Sultana, M. S. and Mahasin, M. 2019. Farmers' Knowledge on Climate Change Effects in Agriculture. Agricultural Sciences, 10, 386-394. https://doi.org/10.4236/as.2019.103031.

[28] Rahman, M. S. 2001. Knowledge, Attitude and Adoption of the Farmers' Regarding Alok-6201 Hybrid Rice in Sadar Upazila of Mymensingh District. M. S. (Ag. Ext. Ed.) Thesis, Department of Agricultural Extension Education. Bangladesh Agricultural University, Mymensingh. 
[29] Sana, M. C. 2003. Farmers' Knowledge of Shrimp Cultivation in Ashasuni Upazila under Satkhira District. M. S. (Ag. Ext. Ed.) Thesis, Department of Agricultural Extension Education, Bangladesh Agricultural University, Mymensingh.
[30] Sarker, M. R. A. 2002. Farmers' Knowledge of and Attitude towards BRRI Dhan 29 Variety of Rice. M. S. (Ag. Ext. Ed.) Thesis, Department of Agricultural Extension Education, Bangladesh Agricultural University, Mymensingh. 